\title{
An Investigation of Molecular Targeting of MMP-9 for Endometriosis Using
} Algal Bioactive Molecules

\author{
Farnaz Nabiya ${ }^{1}$, Anchana Devi Chenniappan ${ }^{1, *}$, Rajamiriyam Marichamy ${ }^{1}$, \\ MubarakAli Davoodbasha ${ }^{2,3}$ and Jung-Wan Kim ${ }^{3, *}$ \\ ${ }^{1}$ P.G. \& Research Department of Biotechnology, Women's Christian College, Chennai, 600006, Tamil Nadu, India \\ ${ }^{2}$ School of Life Sciences, B.S.Abdur Rahman Crescent Institute of Science and Technology, Chennai, 600048, Tamil Nadu, India \\ ${ }^{3}$ Division of Bioengineering, Incheon National University, 119 Academy-ro, Songdo 1(il)-dong, Yeonsu-gu, Incheon, \\ 22012, Korea \\ *Corresponding Authors: Anchana Devi Chenniappan. Email: dr.anchanababu@gmail.com; Jung-Wan Kim. Email: kjw5864@inu.ac.kr \\ Received: 07 May 2021 Accepted: 08 July 2021
}

\begin{abstract}
Endometriosis is a chronic inflammatory disease that occurs due to the presence of endometrial tissue outside the uterine cavity. It affects from $5 \%$ to $10 \%$ of women of reproductive age. High levels of matrix metalloproteinase (especially MMP-9) have been observed in women suffering from endometriosis. Thus, the aim of this study was to investigate the naturally anti-inflammatory compounds available from an algal source that can target the MMP-9 by various in silico approaches. The target 1L6J (Crystal structure of human matrix metalloproteinase MMP-9) structure was retrieved from the PDB database. Five compounds such as Eckol, Sargafuran, Vitamin E, Docosahexaenoic acid, Fucoidan and Elagolix were selected based on 'Lipinski's rule of five' using the PubChem database. The pharmacokinetics, ADMET properties and biological activity of these compounds were predicted computationally using databases such as PreADME, SWISS-ADME, pkCSM and PASS. Comparative analysis of the bioactive compounds with the target was performed by AutoDock 4.2.6. Using LigPlot v.2.2, the target residues interacting with the compounds were visualised in a 2D manner. Based on the results, Eckol exhibited the highest binding energy value of $-7.82 \mathrm{kcal} / \mathrm{mol}$, whereas the Elagolix (control drug) showed a binding energy of $-4.88 \mathrm{kcal}$. We conclude that Eckol can be a potent inhibitor of target MMP-9 with least side effects when compared to the control drug. Hence, this compound can be effectively explored by further in vitro and in vivo studies to develop more effective treatments for Endometriosis.
\end{abstract}

\section{KEYWORDS}

Endometriosis; matrix metalloproteinase; anti-inflammatory; PubChem; AutoDock 4.2.6; LigPlot v.2.2; eckol

\section{Introduction}

Endometriosis is an estrogen-dependent gynaecological and chronic inflammatory disease which occurs due to the presence of endometrial tissue outside the uterine cavity that affects $5 \%$ to $10 \%$ of women of reproductive age (between the ages of 15 to 49-year-old), who are approximately 176 million women in the world [1-3]. $15 \%$ to $20 \%$ women are asymptomatic but may have severe symptoms (i.e., some 
people have mild levels of endometriosis but experience severe symptoms). Endometriosis is said to be associated with inflammation, dysmenorrhea, Fabdominal pain, dyspareunia, chronic pelvic pain [4], infertility, menstrual pain and heavy bleeding [3,5], miscarriage [6], implantation failure [7,8], allergies, asthma, and chemical sensitivities.

Matrix Metalloproteinases (MMPs) are inflammatory factors involved in the progression of endometriosis, playing an important role in tumour formation, angiogenesis-associated diseases and degradation of endometrial tissue. Among the different types of MMPs, MMP-9 [also called as Gelatinase B (GELB)] or $92 \mathrm{kDa}$ type IV collagenase or $92 \mathrm{kDa}$ gelatinase belong to the zincmetalloproteinase family. They are involved in the degradation of the extracellular matrix [9]. The MMP9 levels in patients with type IV endometriosis are comparatively higher than those with types I and II endometriosis, as well as in patients without endometriosis [10]. Therefore, MMP-9 is considered an important biomarker for endometriosis which affects endothelial cell proliferation, migration, and permeability. The protein Tyrosine Kinase 7 (PTK7), via activation of an unidentified RPTK and Src, has been known to activate the mitogen-activated protein kinase (MAPK) [11,12] and NF-kappaB pathways [13]. These have been involved in the upregulation of MMP-9. MAP3K further activates ERK and JNK pathways which in turn activate the AP-1 complex components c-Fos and c-Jun (Table 1). Nuclear factor kappaB $(\mathrm{NF \kappa B})$ and activator protein 1 (AP1) are the transcription factors that bind to the DNA of ectopic and endometriotic cells and transactivate the MMP-9 which enhances the invasive phenotypes of the cells.

A treatment for endometriosis include laparoscopic surgery to remove the endometrial tissue. However, there are cases where the endometriosis tissue returns even after surgery, i.e., recurrent lesions can occur within a few years [14]. This is because z pain medications are a preferred choice of treatment to reduce the pain and provide relief to women suffering from endometriosis. Elagolix, sold under the brand name Orilissa, is a gonadotropin-releasing hormone $(\mathrm{GnRH})$ antagonist [15] which was approved for medical use in July 2018; it is commonly used for treatment of endometriosis [16]. Though endometriosis can be treated effectively with drugs, most of the treatments are not suitable for long-term use due to their side effects [1]. The potential of algal bioactive compounds has not yet been explored. Thus, a wide variety of bioactive compounds were screened by literature review, out of which Eckol, Sargafuran, Vitamin E, Docosahexaenoic acid and Fucoidan were further selected. Thus, the current study discusses the ability of the bioactive compounds from an algal source which can be considered as a novel compound to inhibit the MMP-9, which will in turn help in the treatment of endometriosis.

Table 1: Structure and proposed model pathway of MMP-9

\begin{tabular}{lll}
\hline Note & Model & References \\
\hline 1L6J -Crystal structure of MMP-9 & \\
(3D structure visualization-biovia \\
discovery studio visualizer)
\end{tabular}


Table 1 (continued)

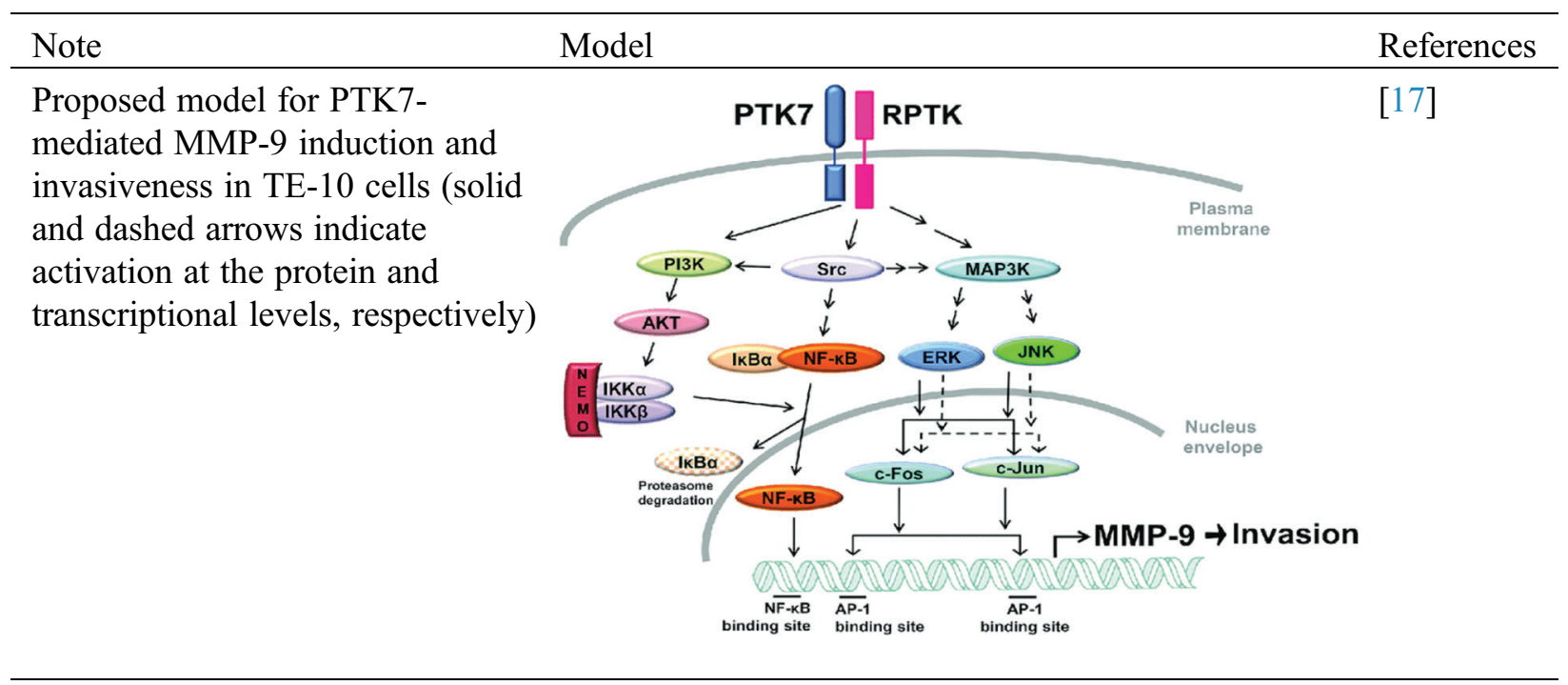

\section{Materials and Methods}

\subsection{Protein Preparation}

For the target selection, the UniProt webpage (https://www.uniprot.org/) was opened. Crystal structure of human MMP-9 with PDB ID 1L6J was downloaded from the Protein Data Bank. Computed Atlas of Surface Topography of Proteins (CAST-P) (http://sts.bioe.uic.edu/castp/index.html?3igg) is an online resource tool useful in predicting the active sites of the target or protein. The active sites were retrieved from this database. The 3D structure of the target protein was visualized using BIOVIA Discovery Studio.

\subsection{Ligand}

\subsubsection{Structure Retrieval of the Ligand Compounds}

$2 \mathrm{D}$ structures of the algal bioactive compounds and control drug-Elagolix were generated from ACD/ ChemSketch (https://www.acdlabs.com/).

\subsubsection{Chemical Properties, Pharmacokinetics, ADMET, Bioactivity Prediction}

- The PubChem (https://pubchem.ncbi.nlm.nih.gov/) is a public repository that contains information on the chemical and drug compounds. The PubChem ID, molecular formula, canonical SMILES, molecular weight, xlog P, Hydrogen Bond Donor, Hydrogen Bond Acceptor, Rotatable Bond Count, and Topological Polar Surface Area were noted.

- $\operatorname{pkCSM}$ (http://biosig.unimelb.edu.au/pkcsm/prediction) is a freely accessible web server and a novel approach in which pharmacokinetic and toxicity properties can be evaluated which aids to develop predictive models for drug development.

- The bioavailability of ligand compounds was predicted using SWISSADME (http://www.swissadme.ch/).

- The carcinogenicity property was predicted by the PreADMET tool (https://preadmet.bmdrc.kr/).

- The bioactivity of each compound was predicted computationally by the PASS (Prediction of Activity Spectra for Substances) tool (http://www.pharmaexpert.ru/passonline/index.php). The compound prediction was clicked and the SMILES retrieved from PubChem was pasted in the search box, and the activities along with the anti-inflammatory property of each compound were noted. 


\subsection{Open Babel}

By using the Open Babel software, the ligand file which was downloaded in 3D sdf (structure data file) (.mol). was converted to pdb (protein data bank) format for docking.

\subsection{Molecular Docking}

AutoDock (http://autodock.scripps.edu/) is molecular modelling simulation software currently maintained by Scripps Research and is effective for protein-ligand docking. It is designed to predict how small molecules can bind to a receptor of known 3D structure. Molecular docking of the selected five bioactive compounds and MMP-9 target was carried out using AutoDock 4.2.6. The docking procedure consisted of six stages, namely protein preparation, ligand preparation, grid preparation, running the grid, docking file preparation, running AutoDock and analysing docking conformations.

\subsection{Visualization-LigPlot v.2.2}

LigPlot is a computer program that is used to visualize the 2-D representations of protein-ligand complexes from standard pdb file input. The molecular docking results were visualized using LigPlot v.2.2. The hydrogen bonds and hydrophobic contacts formed were noted. The current study involves various in silico tools as depicted in the Fig. 1.

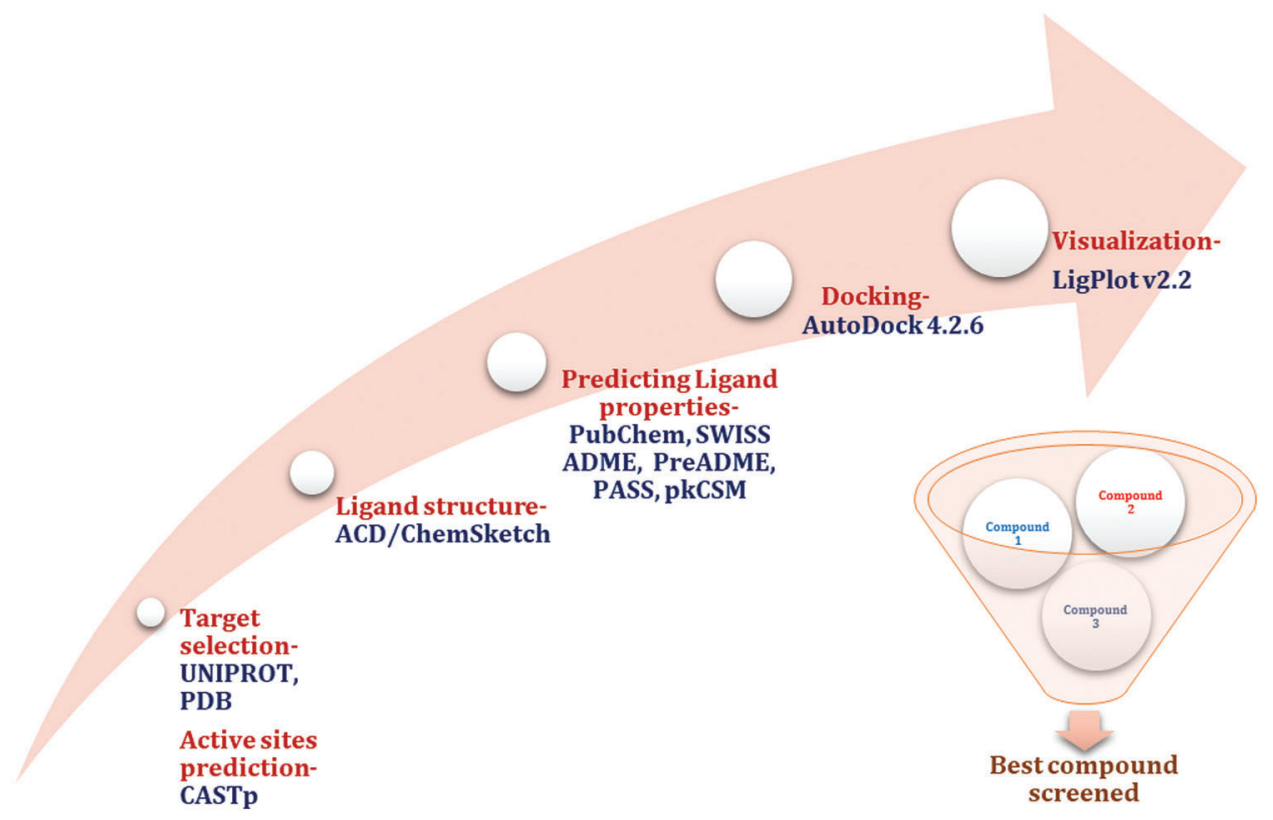

Figure 1: Overview of the in silico tools used in the study

\section{Results and Discussion}

Previous studies have shown that various immunological factors $[18,19]$ play an important role in the pathophysiology of endometriosis and has been involved in the upregulation of cytokines such as TNF- $\alpha$ [20], interleukin-1 $\beta$, IL6, IL8, macrophage migration inhibitory factor (MIF), monocyte chemoattractant protein 1(MCP1), granulocyte, macrophage colony stimulating factor (GM-CSF), IL-1beta, IL4, nitric oxide (NO) and vascular endothelial growth factor (VEGF). MMPs [21] have also been known to play an important role in the pathophysiology of endometriosis. 


\subsection{Selection of the Ligand Compounds}

Elagolix, which is commonly used in treatment of moderate to severe pain associated with endometriosis was selected as a control drug in this in silico study. The other drugs such as Lupron and Synarel takes about 7 to 14 days to be effective, whereas Elagolix (Orilissa) is said to be immediately effective (https://www. goodrx.com/blog/prescription-medications-endometriosis-pain-treatment-birth-control-lupron-orilissa/).

Though endometriosis can be effectively treated with these drugs, most of the treatments are not suitable for long-term use due to their side effects [1]. Because of this reason, the natural bioactive compounds could be explored which is of natural origin with least side effects. Since the potential of bioactive compounds from an algal source has not yet been discovered for treatment of endometriosis, this study focuses to find the algal bioactive compounds that can be explored as novel MMP-9 inhibitors. Five compounds such as Eckol, Sargafuran, Vitamin E, Docosahexaenoic acid and Fucoidan were selected for this study. Their representative source (Tab. S1) and its role (Table 2) have been discussed.

Table 2: Role of bioactive compounds from literature review

\begin{tabular}{|c|c|c|}
\hline $\begin{array}{l}\text { Algal bioactive } \\
\text { compounds }\end{array}$ & Activity & References \\
\hline Eckol & $\begin{array}{l}\text { Down-regulates the proinflammatory enzymes, iNOS and COX-2, } \\
\text { through the negative regulation of the NF- } \mathrm{B} \text { pathway in } \mathrm{A} \beta 25-35- \\
\text { stimulated } \mathrm{PC} 12 \text { cells } \\
\text { There is not any work done pertaining to its role in endometriosis. }\end{array}$ & [22] \\
\hline Sargafuran & $\begin{array}{l}\text { A novel anti-Propionibacterium acnes compound } \\
\text { There is not any work done related to its role in endometriosis. }\end{array}$ & {$[23]$} \\
\hline $\begin{array}{l}\text { Vitamin } \mathrm{E}(\alpha- \\
\text { tocopherol) }\end{array}$ & $\begin{array}{l}\text { It had been shown to reduce pelvic pain and had significant improvement } \\
\text { in women suffering from dysmenorrhea and dyspareunia }\end{array}$ & {$[24,25]$} \\
\hline $\begin{array}{l}\text { Docosahexaenoic } \\
\text { acid }\end{array}$ & $\begin{array}{l}\text { Shown to slow down the growth of endometriotic implants and possess } \\
\text { anti-inflammatory properties. }\end{array}$ & {$[26,27]$} \\
\hline \multirow[t]{5}{*}{ Fucoidan } & Downregulates the activity of MMPs (MMP-2, MMP-9) & {$[28]$} \\
\hline & $\begin{array}{l}\text { Had shown to exhibit anti-proliferative and anti-inflammatory effects } \\
\text { which wereseen to inhibit the progression of epithelial-to-mesenchymal } \\
\text { transition (EMT) and induce apoptosis, thus aiding in the treatment of } \\
\text { endometriosis. }\end{array}$ & \\
\hline & Inhibited E2-induced proliferation of End1/E6E7 and Vk2/E6E7 cells. & \\
\hline & $\begin{array}{l}\text { Decreased expression of the anti-apoptosis protein Bcl- } 2 \text { and increased } \\
\text { the expression of Bax. }\end{array}$ & [29] \\
\hline & $\begin{array}{l}\text { Inhibited inflammation by regulating the levels of VEGFIL-1 } \beta \text { and TNF- } \\
\alpha \text { and suppressed EMT in endometriosis mice. }\end{array}$ & \\
\hline
\end{tabular}

These bioactive compounds were selected on the basis of whether the compound was seen to follow the Lipinski's rule. A drug is said to be active if there are no more than one violation seen. Lipinski rule states that the compound is effective if the molecular weight is less than $500 \mathrm{~g} / \mathrm{mol}$, octanol-water partition coefficient $(\log \mathrm{P})$ is less than 5 , hydrogen bond donors are less than 5 and hydrogen bond acceptors are less than 10 . 


\subsection{Properties of the Selected Compounds}

The PubChem CID, molecular formula, pharmacokinetic properties of the selected bioactive compounds and the control drug have been mentioned in the Table 3.

Table 3: Properties of the ligand molecules

\begin{tabular}{|c|c|c|c|c|c|c|}
\hline Compounds & Eckol & Sargafuran & Vitamin E & $\begin{array}{l}\text { Docosahexaenoic } \\
\text { acid }\end{array}$ & Fucoidan & $\begin{array}{l}\text { Elagolix } \\
\text { (control) }\end{array}$ \\
\hline PubChem CID & 145937 & 101464508 & 14985 & 445580 & 92023653 & 11250647 \\
\hline Molecular formula & $\mathrm{C}_{18} \mathrm{H}_{12} \mathrm{O}_{9}$ & $\mathrm{C}_{27} \mathrm{H}_{36} \mathrm{O}_{4}$ & $\mathrm{C}_{29} \mathrm{H}_{50} \mathrm{O}_{2}$ & $\mathrm{C}_{22} \mathrm{H}_{32} \mathrm{O}_{2}$ & $\mathrm{C}_{7} \mathrm{H}_{14} \mathrm{O}_{7} \mathrm{~S}$ & $\mathrm{C}_{32} \mathrm{H}_{30} \mathrm{~F}_{5} \mathrm{~N}_{3} \mathrm{O}_{5}$ \\
\hline MW g/mol & 372.3 & 424.6 & 430.7 & 328.5 & 242.25 & 631.6 \\
\hline $\mathrm{x} \log \mathrm{P}$ & 2.5 & 5.2 & 10.7 & 6.2 & -1.5 & 2.6 \\
\hline HBD & 6 & 2 & 1 & 1 & 3 & 2 \\
\hline HBA & 9 & 4 & 2 & 2 & 7 & 11 \\
\hline $\begin{array}{l}\text { Lipinski rule } \\
\text { violation }\end{array}$ & 1 & 1 & 1 & 1 & 0 & 2 \\
\hline $\mathrm{RBC}$ & 2 & 11 & 12 & 14 & 2 & 12 \\
\hline TPSA $\left(\AA^{2}\right)$ & 149 & 70.7 & 29.5 & 37.3 & 122 & 99.2 \\
\hline Bioavailibility & 0.55 & 0.85 & 0.55 & 0.85 & 0.56 & 0.17 \\
\hline VD $(\log \mathrm{L} / \mathrm{kg})$ & 0.595 & -0.605 & 0.709 & -0.709 & -0.181 & -1.074 \\
\hline CYP3A4 substrate & No & Yes & Yes & Yes & No & Yes \\
\hline AMES toxicity & $\begin{array}{l}\text { Non- } \\
\text { mutagen }\end{array}$ & $\begin{array}{l}\text { Non- } \\
\text { mutagen }\end{array}$ & $\begin{array}{l}\text { Non- } \\
\text { mutagen }\end{array}$ & Non-mutagen & $\begin{array}{l}\text { Non- } \\
\text { mutagen }\end{array}$ & Non-mutagen \\
\hline Hepatotoxicity & No & No & No & Yes & No & Yes \\
\hline Carcinogenicity & Negative & Positive & Negative & Positive & Negative & Positive \\
\hline
\end{tabular}

Notes: MW-Molecular weight, HBD-Hydrogen bond donor, HBA-Hydrogen bond acceptor, RBC-Rotatable bond count, TPSA-Topological polar surface area, VD-Volume Distribution.

The following parameters retrieved from PubChem, SWISSADME, pkCSM and PreADMET databases have been further discussed:

- As the molecular weight increases, the permeability of the compound decreases, which in turn decreases the bioavailability of it. The molecular weight of all the compounds, except the control drug Elagolix, was seen to be less than $500 \mathrm{~g} / \mathrm{mol}$.

- Log P also known as octanol water partition, is commonly used to measure the liphophilicity. It indicates the permeability of the drug to reach the target tissue. It helps in determining solubility, adsorption and membrane penetration.

- The hydrogen bond donor and acceptor are an important criteria to determine the ligand's specificity towards the receptor.

- An ideal compound should have Hydrogen Bond Donor (HBD) less than 5.

- Hydrogen Bond Acceptor (HBA) of an ideal compound is always less than 10. Only the Elagolix (control drug) had HBA value of more than 10.

These results indicate that the bioactive compounds had no more than one violation seen where the Elagolix drug had two violations in Lipinski's rule. This indicates that it is not an ideal drug whereas the 
remaining bioactive compounds seemed to violate only one rule as a maximum. This indicates that bioactive compounds from the algal sources can be studied.

- If the volume of distribution ( $\mathrm{Vd}$ ) value is below $-0.15 \log \mathrm{L} / \mathrm{kg}$, it is considered low. If $\mathrm{Vd}$ is more than $0.45 \log \mathrm{L} / \mathrm{kg}$ it is considered high. Elagolix had the lowest Vd value.

- Number of Rotatable Bonds (nrotb/RBC) is an important parameter to measure the molecular flexibility and oral bioavailability of drugs.

- Topological Polar Surface Area (TPSA) is the sum of all polar atoms present in the molecule which can help in determining the drug ability to penetrate the cells.

- If the bioavailability is 0.55 and above, it is said to follow the Lipinski's rule, and it is considered a good oral bioactive drug. This parameter was predicted using SWISS-ADME. The bioavailability of the bioactive compounds was equal to or more than 0.55 . The control drug had very low bioavailability (0.17), thus, indicating the search for new drugs in Endometriosis treatment.

- AMES test determined whether the bioactive compound was either mutagenic or not. All compounds were shown to be non-mutagenic.

- Hepatotoxicity helps in predicting whether the compound will disrupt the normal functional activity of the liver if the drug dosage is taken in high amount. Docosahexaenoic acid and Elagolix were found to be hepatotoxic whereas the remaining compounds were found to be non-hepatotoxic.

\subsection{Structure Retrieval of the Ligand Compounds}

The 2D structures of the algal (Figs. 2A-2E) bioactive compounds and control Drug-Elagolix (Fig. 2F) were generated from the ACD/ChemSketch software.

\subsection{Bioactivity Prediction Using PASS}

$\mathrm{Pa}$ (probability "to be active") helps in predicting the bioactivity of the compounds. The activities that were having a Pa value above 0.7 were tabulated (Tab. S2), indicating that the compound as highly active to perform the specific activity; the anti-inflammatory activity of each compound was noted. The results based on PASS indicated that the selected five bioactive compounds showed various activities when the $\mathrm{Pa}$ was above 0.7, whereas the Elagolix exhibited no activity when the Pa value was above 0.7.

\subsection{Molecular Docking}

Docking was performed with the Crystal structure of human matrix metalloproteinase MMP9 (gelatinase B) [MMP9: PDB 1L6J [30]] and bioactive compounds. A previous docking study by Maurya et al. [31] on the target 1L6J (Crystal Structure of Metalloproteinases 9) was efficiently studied as a neuroprotectant compound against cerebral ischemia.

Molecular docking and comparative analysis of the selected bioactive compounds and the control drug were performed using the software AutoDock 4.2.6. Prior to docking, the solvent molecules were removed from the structure of the target and the active sites residues in the target were retrieved using CASTp. Each compound was docked individually and the results obtained from each docking were tabulated as shown in Table 4.

The docking results provided information on the following parameters such as the Binding energy (Fig. 3), Ligand efficiency, Intermolecular energy, Vander Waal's dissolved energy, Electrostatic energy, etc. 
(A)<smiles>Oc1cc(O)cc(Oc2c(O)cc(O)c3c2Oc2c(O)cc(O)cc2O3)c1</smiles>

(D)

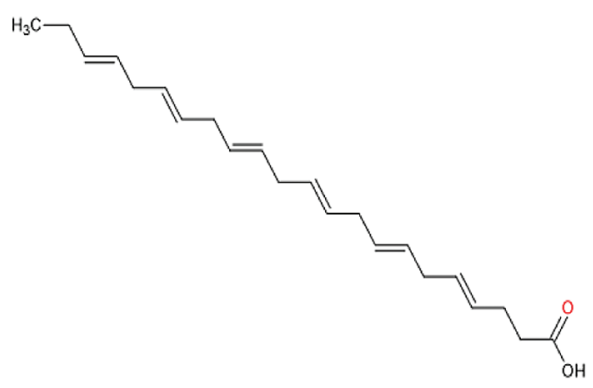

(B)<smiles>CC(C)=CCC/C(=C\CC/C(C)=C/CCC1=C(c2ccc(C)o2)C=CC1(C)O)C(=O)O</smiles>

(E)<smiles>CC1OC(C)C(OS(=O)(=O)O)C(O)C1O</smiles>

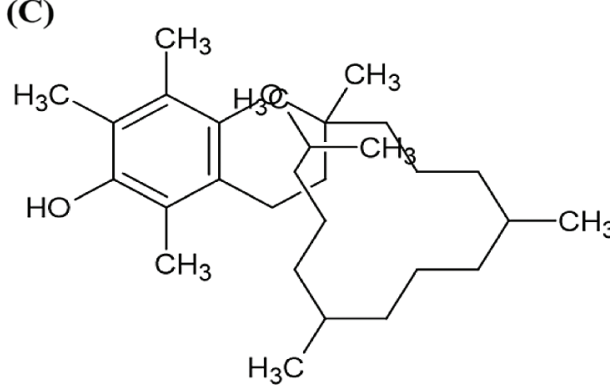

(F)

Figure 2: 2D Structures of the ligand compounds generated from ACD/ChemSketch: (A) Eckol, (B) Sargafuran, (C) Vitamin E, (D) Docosahexaenoic acid, (E) Fucoidan and (F) Control drug-elagolix

Table 4: Summary of docking results obtained from bioactive compounds and drugs screened against MMP-9

\begin{tabular}{lllllllll}
\hline $\begin{array}{l}\text { Molecular docking } \\
\text { of MMP-9 with }\end{array}$ & $\begin{array}{l}\text { Binding } \\
\text { energy } \\
(\mathrm{kcal} / \mathrm{mol})\end{array}$ & $\begin{array}{l}\text { No. of } \\
\text { hydrogen } \\
\text { bonds }\end{array}$ & $\begin{array}{l}\text { Ligand } \\
\text { efficiency }\end{array}$ & $\begin{array}{l}\text { Intermolecular } \\
\text { energy }\end{array}$ & $\begin{array}{l}\text { vdW }+\mathrm{hb}+ \\
\text { desolvenergy }\end{array}$ & $\begin{array}{l}\text { Electrostat } \\
\text { cenery }\end{array}$ & $\begin{array}{l}\text { Torsional } \\
\text { energy }\end{array}$ & $\begin{array}{l}\text { Total } \\
\text { internal } \\
\text { unboud }\end{array}$ \\
\hline Eckol & -7.82 & 7 & -0.29 & -10.21 & -9.6 & -0.61 & 2.39 & -2.52 \\
Sargafuran & -7.36 & 3 & -0.24 & -11.23 & -10.84 & -0.4 & 3.88 & -2.27 \\
Vitamin E & -7.12 & 1 & -0.23 & -11.00 & -10.79 & -0.21 & 3.88 & -2.17 \\
Docosahexaenoic & -6.83 & 1 & -0.28 & -11.31 & -9.68 & -1.63 & 4.47 & -0.9 \\
acid & & & & & & & & \\
Fucoidan & -6.08 & 2 & -0.41 & -7.57 & -7.48 & -0.09 & 1.49 & -4.05 \\
Elagolix & -4.88 & 1 & -0.11 & -9.06 & -8.69 & -0.37 & 4.18 & -5.56 \\
\hline
\end{tabular}

The bioactive compounds such as Eckol, Sargafuran, Vitamin E, Docosahexaenoic acid and Fucoidan exhibited binding energy values of $-7.82,-7.36,-7.12,-6.83$ and $-6.08 \mathrm{kcal} / \mathrm{mol}$, whereas the control drug Elagolix exhibited the lowest binding energy value of $-4.88 \mathrm{kcal} / \mathrm{mol}$. Also, ligand efficiency, number of 
hydrogen bonds formed and the other interactions such as Vanderwaal force, Intermolecular energy, Torsional energy, and total internal unbound energy were seen.

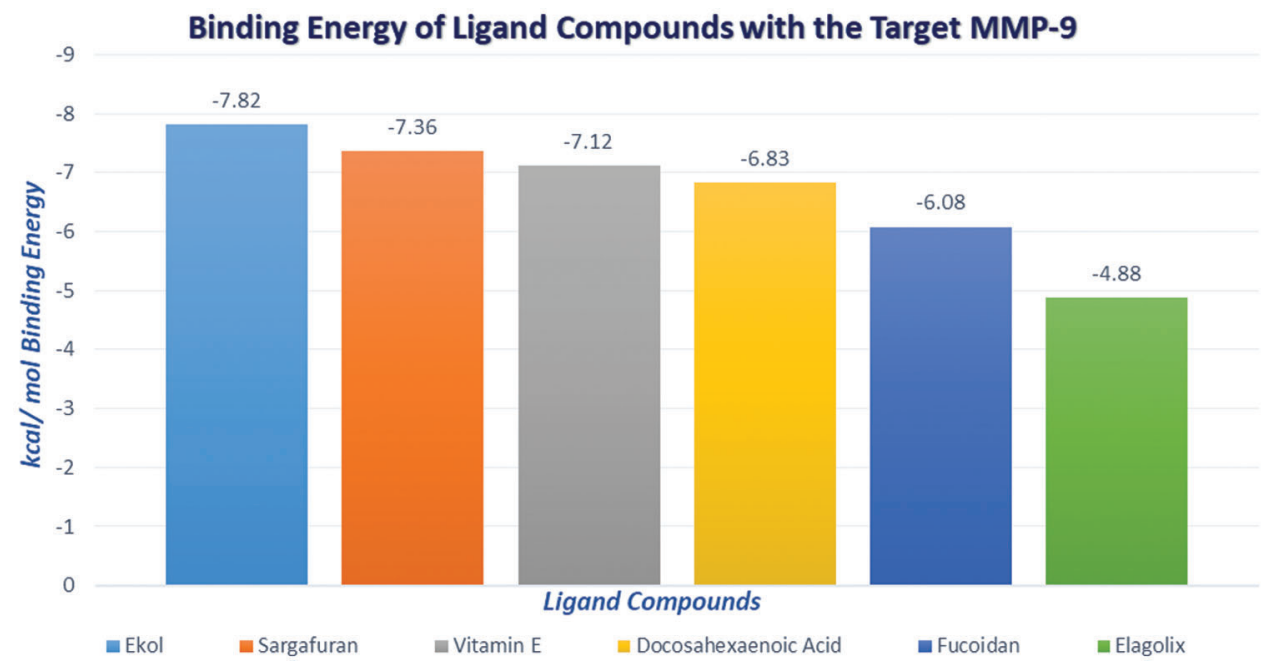

Figure 3: Graph illustrating the comparative analysis of binding energies of ligand compounds with the target MMP-9

\subsection{Visualization by LigPlot v.2.2}

The docking results can be analyzed using LigPlot v.2.2 which provides the information about the receptor-ligand interaction and the hydrogen bonds formed. The interactions formed via the hydrogen bonds between the receptor and the compound were visualized in a $2 \mathrm{D}$ manner using the LigPlot v.2.2 software. The LigPlot v.2.2 provides information on the distance of hydrogen bonds formed, and on the target interacting with the nearby metabolites (Table 5).

Table 5: Visualization by LigPlot + v.2.2

\begin{tabular}{|c|c|c|}
\hline $\begin{array}{l}\text { Molecular docking } \\
\text { of MMP-9 with }\end{array}$ & $\begin{array}{l}\text { Amino acids with hydrogen } \\
\text { bonds }\end{array}$ & Amino acids with hydrophobic interactions \\
\hline Eckol & $\begin{array}{l}\text { Glu274, Ser273, Arg332, } \\
\text { Phe349 }\end{array}$ & Gly252, Arg275, Cys244, Thr245, Thr246 \\
\hline Sargafuran & Arg134, Ala333, Thr331 & $\begin{array}{l}\text { Val313, Val316, Val317, Pro373, Pro133, Asp131, } \\
\text { Arg333, Tyr377, Pro389, Leu133, Glu130, Ser139 }\end{array}$ \\
\hline Vitamin E & Glu130 & $\begin{array}{l}\text { Arg134, Tyr135, Ser139, Leu133,Pro133, Ala333, } \\
\text { Tyr377, Pro349, Pro373, Thr331, Pro330 }\end{array}$ \\
\hline $\begin{array}{l}\text { Docosahexaenoic } \\
\text { acid }\end{array}$ & Lys92 & $\begin{array}{l}\text { Arg93, Tyr423, His401, Pro421, Leu393, Cys99, } \\
\text { Leu418, Tyr420, Met433, Arg434, Ala417, Val398, } \\
\text { Pro415, Glu415 }\end{array}$ \\
\hline Fucoidan & $\begin{array}{l}\text { His401, Tyr420, Pro415, } \\
\text { Ala417, Met422, Arg424 }\end{array}$ & Leu418, Val398, Tyr423, Leu397 \\
\hline Elagolix & $\operatorname{Arg} 143$ & $\begin{array}{l}\text { Tyr138, Leu133, Pro133, Glu130, Tyr311, Ser139, } \\
\text { Asp131, Val307, Thr334, Pro373, Val383, Pro389, } \\
\text { Ala333 }\end{array}$ \\
\hline
\end{tabular}


The hydrophobic interactions are the most common type of interaction seen in the protein-ligand complex and are said to be stronger than hydrogen bond, Vander Waal's forces and intermolecular energy. The MMP-9 target residues interacting with the bioactive metabolites and the control drugs has been visualized (Figs. 4A-4F).

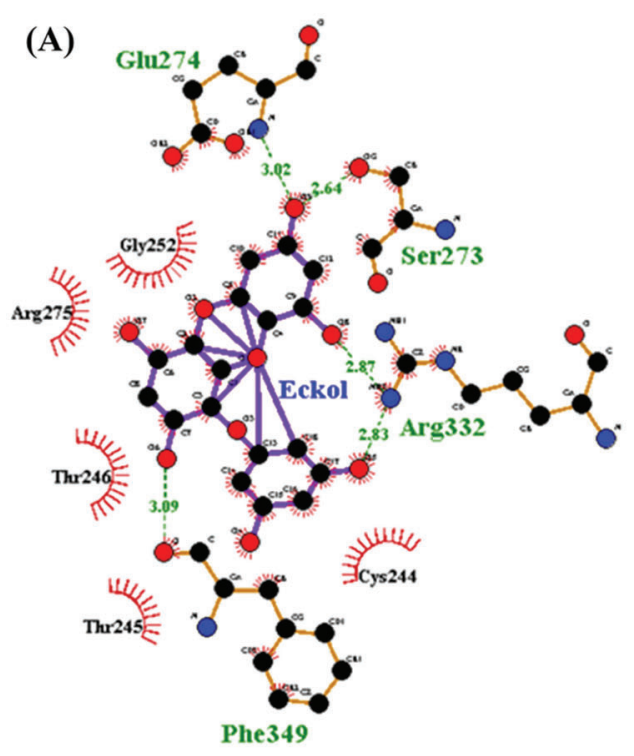

1L6J (MMP-9)

(C)

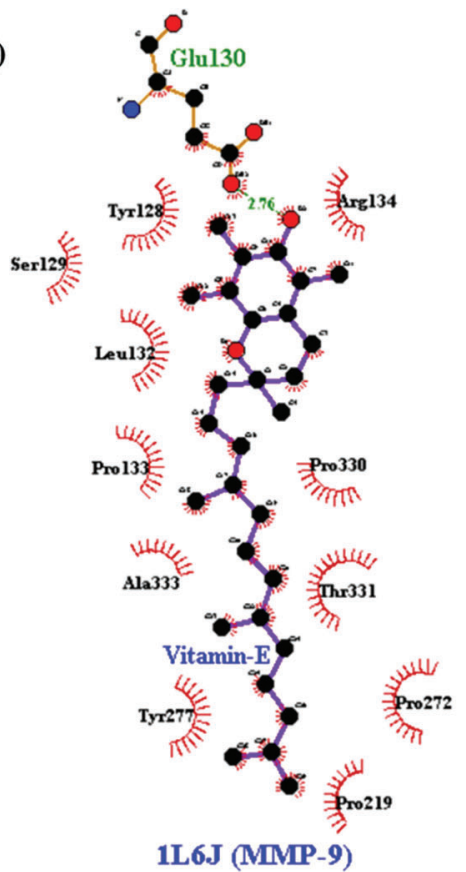

(B)

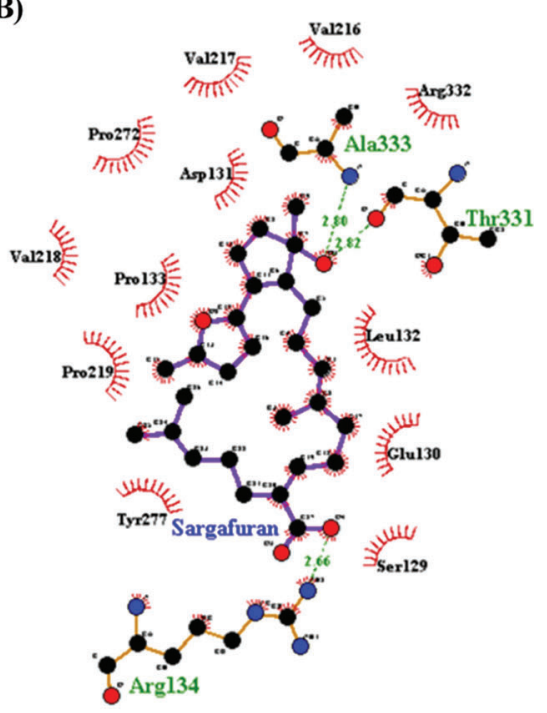

1L6J (MMP-9)

(D)

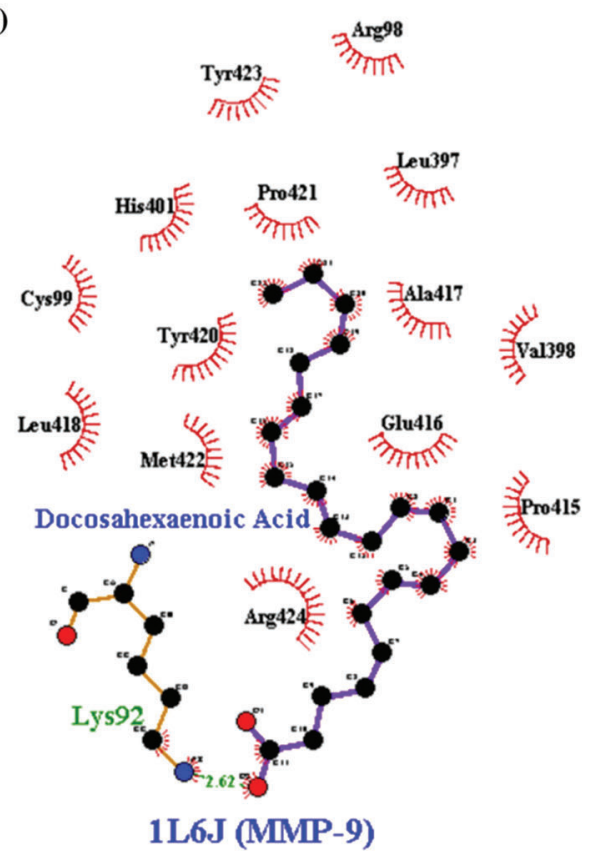

Figure 4: Continued 

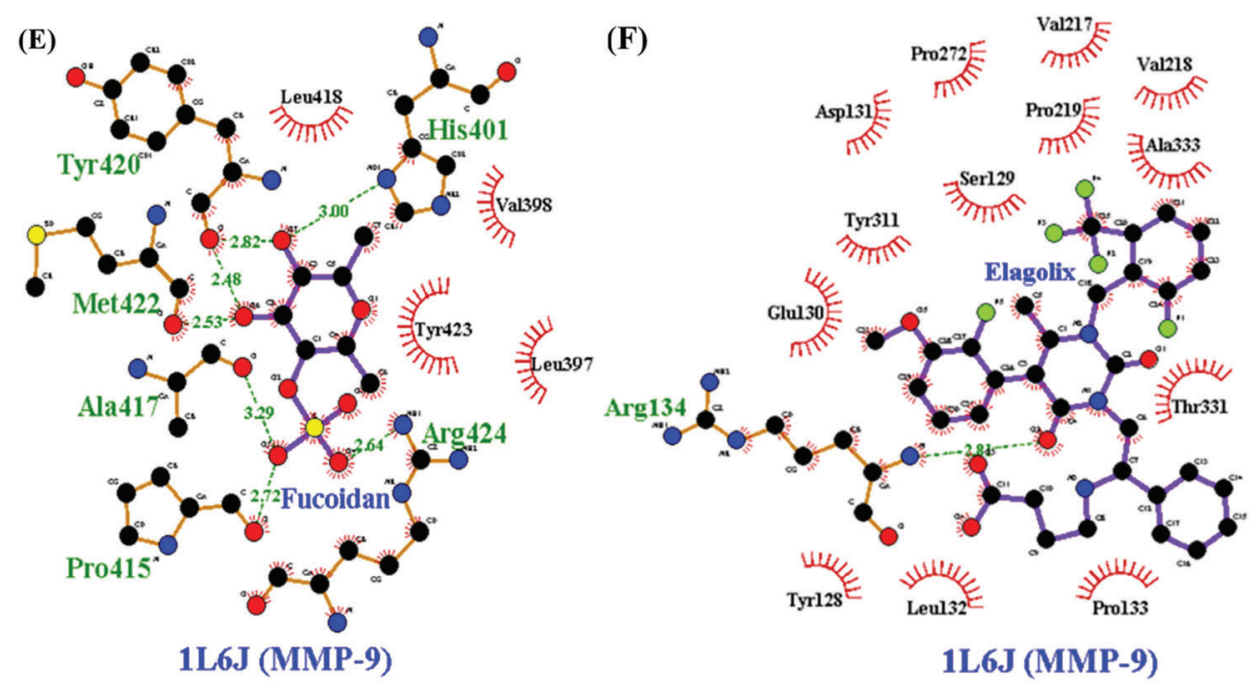

Figure 4: Visualization by LigPlot + v.2.2 of MMP-9 with (A) Eckol, (B) Sargafuran, (C) Vitamin E, (D) Docosahexaenoic Acid, (E) Fucoidan, and (F) Elagolix

Thus, this in silico study demonstrated that the bioactive compounds showed a better binding energy comparative to the control drug. Collectively, these results encourage further research of the novel drug from the algal source which will effectively act against the MMP-9 receptor in the endometriosis treatment. These compounds should be further investigated for its role in the wet laboratory studies.

\section{Conclusion and Future Perspectives}

The algal bioactive compounds can be explored as novel leading compounds which can inhibit the levels of MMP-9 with the least effect for the treatment of endometriosis. Based on the properties prediction, it can be concluded that all the selected bioactive compounds did not violate more than one Lipinski's rule; only the control drug was seen to have more than one violation. When computationally predicted using the PASS database, it was shown that most of the bioactive compounds exhibited several activities when the Pa value was above 0.7 ; the control drug exhibited no activity. Also, the bioavailability of the control drug was very low, which indicated that this drug showed poor absorption. All the bioactive compounds showed a bioavailability higher than or equal to 0.55 . Toxicity, carcinogenic and bioavailability of the compounds were predicted computationally by pkCSM, PreADME and SWISSADME, respectively. The molecular docking was performed using AutoDock 4.2.6 and visualization was done using LigPlot v.2.2. Based on the docking results, Eckol was the compound that exhibited the highest binding energy of $-7.82 \mathrm{kcal} / \mathrm{mol}$ whereas the control drug-Elagolix exhibited a low binding energy of $-4.88 \mathrm{kcal} / \mathrm{mol}$. Therefore, it can be concluded that the algal compound. Eckol can act as a potential leading compound for designing a novel therapeutic drug. Also, it can be further investigated for its role which will effectively act against the MMP-9 receptor with the ultimate goal in the treatment of endometriosis.

Acknowledgement: This study was supported by the grant from Incheon National University, 2018. We express our sincere thanks and gratitude to Dr. Shoba Pradeep for sharing knowledge during the docking studies.

Author Contributions: Farnaz Nabiya and Dr. Anchana Devi C. participated in the design of the study. Farnaz Nabiya performed the docking, visualization analysis and wrote the manuscript. Farnaz Nabiya, Dr. Anchana Devi C. and Rajamiriyam M. revised the manuscript to be published. 
Funding Statement: The authors received no specific funding for this study.

Conflicts of Interest: The authors declare that they have no conflicts of interest to report regarding the present study.

\section{References}

1. Rogers, P. A. W., Adamson, G. D., Al-Jefout, M., Becker, C. M., D’Hooghe, T. M. et al. (2017). Research priorities for endometriosis: Recommendations from a global consortium of investigators in endometriosis. Reproductive Sciences, 24(2), 202-226. DOI 10.1177/1933719116654991.

2. Rogers, P. A. W., D’Hooghe, T. M., Fazleabas, A., Gargett, C. E., Giudice, L. C. et al. (2009). Priorities for endometriosis research: Recommendations from an international consensus workshop. Reproductive Sciences, 16(4), 335-346. DOI 10.1177/1933719108330568.

3. Burney, R. O., Giudice, L. C. (2012). Pathogenesis and pathophysiology of endometriosis. Fertility and Sterility, 98(3), 511-519. DOI 10.1016/j.fertnstert.2012.06.029.

4. Mao, A. J., Anastasi, J. K. (2010). Diagnosis and management of endometriosis: The role of the advanced practice nurse in primary care. Journal of the American Academy of Nurse Practitioners, 22(2), 109-116. DOI 10.1111/ j.1745-7599.2009.00475.x.

5. Zondervan, K. T., Becker, C. M., Koga, K., Missmer, S. A., Taylor, R. N. et al. (2018). Endometriosis. Nature Reviews. Disease Primers, 4(1), 9. DOI 10.1038/s41572-018-0008-5.

6. Santi, M., Maccari, G., Mereghetti, P., Voliani, V., Rocchiccioli, S. et al. (2017). Rational design of a transferrinbinding peptide sequence tailored to targeted nanoparticle internalization. Bioconjugate Chemistry, 28(2), 471480. DOI 10.1021/acs.bioconjchem.6b00611.

7. Margalioth, E. J., Ben-Chetrit, A., Gal, M., Eldar-Geva, T. (2006). Investigation and treatment of repeated implantation failure following IVF-ET. Human Reproduction, 21(12), 3036-3043. DOI 10.1093/humrep/del305.

8. Tomassetti, C., Meuleman, C., Pexsters, A., Mihalyi, A., Kyama, C. et al. (2006). Endometriosis, recurrent miscarriage and implantation failure: Is there an immunological link? Reproductive Biomedicine Online, 13(1), 58-64. DOI 10.1016/S1472-6483(10)62016-0.

9. Parks, W. C. (2006). Matrix metalloproteinases. Encyclopedia of respiratory medicine, pp. 311-318. Academic Press, Elsevier. DOI 10.1016/B0-12-370879-6/00234-9.

10. Liu, H., Wang, J., Wang, H., Tang, N., Li, Y. et al. (2015). Correlation between matrix metalloproteinase-9 and endometriosis. International Journal of Clinical and Experimental Pathology, 8(10), 13399-13404.

11. Wang, T., Liao, Y., Sun, Q., Tang, H., Wang, G. et al. (2017). Upregulation of matrix metalloproteinase-9 in primary cultured rat astrocytes induced by 2-chloroethanol via MAPK signal pathways. Frontiers in Cellular Neuroscience, 11, 218. DOI 10.3389/fncel.2017.00218.

12. Reddy, K. B., Krueger, J. S., Kondapaka, S. B., Diglio, C. A. (1999). Mitogen-activated protein kinase (MAPK) regulates the expression of progelatinase B (MMP-9) in breast epithelial cells. International Journal of Cancer, 82(2), 268-273. DOI 10.1002/(ISSN)1097-0215.

13. Cheng, C. Y., Hsieh, H. L., Hsiao, L. D., Yang, C. M. (2012). PI3-K/Akt/JNK/NF-kB is essential for MMP9 expression and outgrowth in human limbal epithelial cells on intact amniotic membrane. Stem Cell Research, 9(1), 9-23. DOI 10.1016/j.scr.2012.02.005.

14. Alkatout, I., Mettler, L., Beteta, C., Hedderich, J., Jonat, W. et al. (2013). Combined surgical and hormone therapy for endometriosis is the most effective treatment: Prospective, randomized controlled trial. Journal of Minimally Invasive Gynecology, 20(4), 473-481. DOI 10.1016/j.jmig.2013.01.019.

15. Kim, S. M., Lee, M., Lee, S. Y., Park, E., Lee, S. M. et al. (2016). Discovery of an orally bioavailable gonadotropin-releasing hormone receptor antagonist. Journal of Medicinal Chemistry, 59(19), 9150-9172. DOI 10.1021/acs.jmedchem.6b01071. 
16. Food and Drug Administration (2018). New drug therapy approvals. Silver Spring: U.S. Food and Drug Administration (FDA).

17. Shin, W. S., Hong, Y., Lee, H. W., Lee, S. T. (2016). Catalytically defective receptor protein tyrosine kinase PTK7 enhances invasive phenotype by inducing MMP-9 through activation of AP-1 and NF- $\mathrm{KB}$ in esophageal squamous cell carcinoma cells. Oncotarget, 7(45), 73242-73256. DOI 10.18632/oncotarget.12303.

18. Barrier, B. F. (2010). Immunology of endometriosis. Clinical Obstetrics and Gynecology, 53(2), 397-402. DOI 10.1097/GRF.0b013e3181db7c33.

19. Riccio, L., Santulli, P., Marcellin, L., Abrão, M. S., Batteux, F. et al. (2018). Immunology of endometriosis. Best practice \& research. Clinical Obstetrics \& Gynaecology, 50(3), 39-49. DOI 10.1016/j.bpobgyn.2018.01.010.

20. Grund, E. M., Kagan, D., Tran, C. A., Zeitvogel, A., Starzinski-Powitz, A. et al. (2008). Tumor necrosis factoralpha regulates inflammatory and mesenchymal responses via mitogen-activated protein kinase kinase, $\mathrm{p} 38$, and nuclear factor kappaB in human endometriotic epithelial cells. Molecular Pharmacology, 73(5), 1394-1404. DOI 10.1124/mol.107.042176.

21. Osteen, K. G., Yeaman, G. R., Bruner-Tran, K. L. (2003). Matrix metalloproteinases and endometriosis. Seminars in Reproductive Medicine, 21(2), 155-164. DOI 10.1055/s-2003-41322.

22. Lee, S., Youn, K., Kim, D. H., Ahn, M. R., Yoon, E. et al. (2018). Anti-Neuroinflammatory property of phlorotannins from Ecklonia cava on Aß25-35-induced damage in PC12 cells. Marine Drugs, 17(1), 7. DOI 10.3390/md17010007.

23. Kamei, Y., Sueyoshi, M., Hayashi, K., Terada, R., Nozaki, H. (2009). The novel anti-propionibacterium acnes compound, Sargafuran, found in the marine brown alga sargassum macrocarpum. The Journal of Antibiotics, 62(5), 259-263. DOI 10.1038/ja.2009.25.

24. Santanam, N., Kavtaradze, N., Murphy, A., Dominguez, C., Parthasarathy, S. (2013). Antioxidant supplementation reduces endometriosis-related pelvic pain in humans. Translational Research: The Journal of Laboratory and Clinical Medicine, 161(3), 189-195. DOI 10.1016/j.trsl.2012.05.001.

25. Lin, Y. H., Chen, Y. H., Chang, H. Y., Au, H. K., Tzeng, C. R. et al. (2018). Chronic niche inflammation in endometriosis-associated infertility: Current understanding and future therapeutic strategies. International Journal of Molecular Sciences, 19(8), 2385. DOI 10.3390/ijms19082385.

26. Ryan, A. S., Keske, M. A., Hoffman, J. P., Nelson, E. B. (2009). Clinical overview of algal-docosahexaenoic acid: Effects on triglyceride levels and other cardiovascular risk factors. American Journal of Therapeutics, 16(2), 183192. DOI 10.1097/MJT.0b013e31817fe2be.

27. Domingo, P., Gallego-Escuredo, J. M., Fernández, I., Villarroya, J., Torres, F. et al. (2018). Effects of docosahexanoic acid supplementation on inflammatory and subcutaneous adipose tissue gene expression in HIV-infected patients on combination antiretroviral therapy (cART). A sub-study of a randomized, doubleblind, placebo-controlled study. Cytokine, 105(Suppl. 2), 73-79. DOI 10.1016/j.cyto.2018.02.008.

28. Huang, T. H., Chiu, Y. H., Chan, Y. L., Chiu, Y. H., Wang, H. et al. (2015). Prophylactic administration of fucoidan represses cancer metastasis by inhibiting vascular endothelial growth factor (VEGF) and matrix metalloproteinases (MMPs) in Lewis tumor-bearing mice. Marine Drugs, 13(4), 1882-1900. DOI 10.3390/md13041882.

29. Chang, L. C., Chiang, Y. F., Chen, H. Y., Huang, Y. J., Liu, A. C. et al. (2020). The potential effect of fucoidan on inhibiting epithelial-to-mesenchymal transition, proliferation, and increase in apoptosis for endometriosis treatment: In vivo and in vitro study. Biomedicines, 8(11), 528. DOI 10.3390/biomedicines 8110528.

30. Elkins, P. A., Ho, Y. S., Smith, W. W., Janson, C. A., D’Alessio, K. J. et al. (2002). Structure of the C-terminally truncated human ProMMP9, a gelatin-binding matrix metalloproteinase. Acta Crystallographica Section D: Biological crystallography, 58(Pt 7), 1182-1192. DOI 10.1107/S0907444902007849.

31. Maurya, K., Pandey, A. K. (2019). Molecular docking study for evaluation of neuroprotective potential of sericin against cerebral stroke and exploring its biomaterial properties. Biomedical Research Journal, 6(1), 17-24. DOI 10.4103/BMRJ.BMRJ_5_19. 


\section{INTERNET (WEB) LINKS}

1. https://www.news-medical.net/health/What-is-Endometriosis.aspx

2. http://www.globalmd.org/c/journal_articles/view_article_content?articleId=181\&version=1.0\#: : text $=$ The $\% 20$ word $\% 20$ endometriosis $\% 20$ comes $\% 20$ from, $\% 2 \mathrm{C} \% 20$ condition $\% 2 \mathrm{C} \% 20$ abnormal $\%$ 20 process $\% 22$

3. https://www.goodrx.com/blog/prescription-medications-endometriosis-pain-treatment-birth-controllupron-orilissa/

4. https://www.uniprot.org/

5. http://sts.bioe.uic.edu/castp/index.html?3igg

6. https://pubchem.ncbi.nlm.nih.gov/

7. http://biosig.unimelb.edu.au/pkcsm/prediction

8. http://www.swissadme.ch/

9. https://preadmet.bmdrc.kr/

10. http://www.pharmaexpert.ru/passonline/index.php

11. https://www.acdlabs.com/

12. http://autodock.scripps.edu/ 